EL QUIEBRE DEL PENSAMIENTO CRÍTICO

Tomás Moulian Emparanza 
Premio Nacional de Humanidades y Ciencias Sociales 2015. Es sociólogo titulado en la Pontificia Universidad Católica de Chile y Licenciado en Ciencias Sociales de la Universidad Católica de Lovaina. Fue director de la Escuela de Sociología de la Pontificia Universidad Católica de Chile y de la de la Universidad ARCIS, donde también se desempeñó como Vicerrector. Fue subdirector de FLACSO Chile entre 1990 y 1991. Entre sus obras destacan Chile actual. Anatomia de un mito (1997), El consumo me consume (1999) y En la brecha. Derechos humanos, críticas y alternativas (2002). 


\section{EL QUIEBRE DEL PENSAMIENTO CRÍTICO}

\section{PLANTEAMIENTO DEL PROBLEMA}

El principal objetivo de este artículo es describir y analizar el quiebre del pensamiento crítico por efectos de la acción de la dictadura de la Junta Militar.

La primera pregunta a responder es respecto al tipo de dictadura. Habitualmente se le denomina autoritarismo para distinguirla de las dictaduras totalitarias. Pero el régimen militar chileno es una dictadura global. Ella plantea un proyecto de carácter contrarrevolucionario, el cual comprende un programa económico de carácter liberal extremo, un proyecto cultural de carácter conservador y un régimen político dictatorial que dará lugar a una democracia semirrepresentativa.

El proyecto cultural conservador implica la mercantilización, lo que significa que el par dinero-consumo se convierte en sentido predominante de vida. Esa dimensión es reforzada por planteamientos en relación a la sexualidad y la reproducción inspiradas por el catolicismo tradicionalista.

Para instalarse, ese proyecto cultural necesitó el desplazamiento de los proyectos ideológicos que habían marcado a la sociedad chilena, en especial durante la década del 60 del siglo pasado. Ellos son el pensamiento socialcristiano avanzado y el pensamiento de la izquierda.

El primero de los enfoques señalados se materializa de manera mitigada en la llamada "revolución en libertad" y el otro en la denominada "vía chilena al socialismo".

Esos dos enfoques ideológicos intentan ser sustituidos por concepciones mercantiles globales. Pero antes de describir y analizar esas ideologías sustitutivas deben abordarse los enfoques en quiebre, esto es, aquellos que se busca dejar de lado.

Serán analizados siguiendo un orden cronológico, tomando en consideración el momento de mayor emergencia. Esto significa que se abordará antes el pensamiento socialcristiano avanzado y luego el pensamiento de la izquierda.

\section{EL ENFOQUE SOCIALCRISTIANO}

El enfoque socialcristiano avanzado plantea la necesidad de pasar de la sociedad capitalista a la sociedad comunitaria. Ese tránsito entre una y otra era de larga duración y debía irse realizando por etapas. 
En ese esquema el primer gobierno democratacristiano debía representar una etapa de reformas de carácter antioligárquico entre las cuales las más importantes tenían relación con la agricultura. Ellas fueron la ampliación de la reforma agraria y el desarrollo de la sindicalización campesina.

Este enfoque ideológico planteaba que era necesario construir una "nueva cristiandad", la que daría lugar a una sociedad fraternal y solidaria.

Los principales ideólogos de esta tendencia eran Eduardo Frei, Jaime Castillo, Julio Silva y Jacques Chonchol. Los dos últimos preferían hablar de socialismo comunitario y se situaban en la izquierda de la Democracia Cristiana, partido del que finalmente se retiran.

El planteamiento socialcristiano se inspira en la doctrina social de la Iglesia y el pensamiento católico francés de los años 40 y 50 del siglo XX. En ese país los planteamientos señalados eran formulados por Leon Bloy, una especie de profeta, quien realizaba, con lenguaje apocalíptico, una crítica de la moral y la cultura burguesa. También eran sostenidos por el pensador neotomista Jacques Maritain y por el intelectual personalista Emmanuel Mounier, director de la revista Esprit.

Ambos eran críticos de las sociedades capitalistas, las que analizaban especialmente a la luz de la patrística. Es importante señalar que estos ideólogos escriben sus críticas en un período previo al Concilio Vaticano II.

Como se dijo, el gobierno de Frei Montalva pone en práctica un programa de reformas de contenido antioligárquico. Esto lo lleva a enfrentarse con la derecha, la que lo había apoyado en la elección presidencial.

La puesta en aplicación de ese programa genera el corrimiento de la derecha y de la izquierda hacia la izquierda.

El primer desplazamiento se produce porque la derecha política representaba a la burguesía industrial, comercial y financiera, pero también a los latifundistas, directamente afectados por el programa agrario del gobierno.

Al producirse el golpe de estado de 1973 el enfoque comunitarista de la Democracia Cristiana es silenciado. Con anterioridad se había debilitado en el Partido Democratacristiano como consecuencia de la ruptura de mayo de 1969, la cual da lugar a la fundación del MAPU, y la de 1971, la cual da lugar a la creación de la Izquierda Cristiana.

\section{EL ENFOQUE DE LA IZQUIERDA}

La izquierda chilena se autodenominaba marxista en alusión a su impronta ideológica. Era también una tendencia de carácter eurocéntrico. Ella se inspiraba en el pensamiento de Marx, Lenin y el llamado marxismo occidental, para usar el término acuñado por Perry Anderson. 
Gramsci era en Chile prácticamente un desconocido, pese a que algunos de los conceptos por él utilizados, como la noción de hegemonía, hubiesen sido muy útiles para definir el tránsito institucional.

La izquierda chilena de fines de los 50 del siglo pasado planteaba dos enfoques estratégicos distintos.

Pese a ello, en 1956 se había creado el Frente de Acción Popular (FRAP), una alianza de largo plazo de socialistas y comunistas. Los primeros, divididos en dos partidos, recién se unifican un poco después, en 1957, mientras los comunistas son legalizados en 1958. Habían sido prohibidos en 1948 por González Videla.

Uno de los enfoques estratégicos señalados, el del Partido Comunista, planteaba frentes amplios, con presencia del partido laico de centro, el Radical, mientras el Partido Socialista postulaba el frente de trabajadores, una alianza más estrecha.

Al crearse en 1969 la Unidad Popular primó la postura más abierta, pues se sumó el Partido Radical, organización entonces reformista.

Sin embargo, el programa formulado en esa ocasión para el potencial gobierno de Allende incluía medidas de carácter socialista, como la creación de la llamada área de propiedad social, la cual debería estar integrada por los bancos y las más importantes empresas monopólicas, cifradas estas últimas en 91.

Estas medidas habían estado ausentes en los programas de las anteriores campañas presidenciales enfrentadas por Allende, las de 1952, 1958 y 1964.

Pese a la incorporación al programa de 1970 de ese tipo de medidas, el gobierno de la Unidad Popular presentó un intento de avanzar hacia el socialismo por la vía pacífica y a través de un tránsito institucional. Se genera un proceso democrático y pluralista, caracterizado de esa manera por Allende en su discurso al Congreso Pleno del 21 de mayo de 1971.

Pese a ello, durante el corto lapso que alcanzó a durar el gobierno de Salvador Allende se desarrollan dos estrategias, enfrentadas entre sí.

Una era moderada y se expresaba en el eslogan "avanzar para consolidar". La otra era radicalizada y se expresaba en el eslogan "avanzar sin transar".

Salvador Allende, el Partido Comunista, un sector del Partido Socialista, otro del MAPU y el Partido Radical patrocinaban la estrategia moderada mientras otro grupo socialista, junto con la tendencia radicalizada del MAPU y la Izquierda Cristiana planteaban la segunda.

Estas divergencias internas fueron uno de los factores que facilitaron el golpe militar, pues dificultaron la ampliación de la alianza hacia el centro.

No obstante, ninguna de las dos formulaciones, pese a que una era más radical que la otra, abandonan el camino institucional y pacífico.

Las intentonas realizadas en esa dirección fueron rechazadas con fuerza por el máximo líder y en ocasiones incluso por personeros del sector más radicalizado de la coalición. 
El pensamiento de esta izquierda también es reducido al silencio. Siguió desarrollándose en el exilio.

En Chile surge desde 1975 en adelante la tendencia de la renovación socialista, cuyos principales intelectuales políticos trabajaban en FLACSO-Chile.

A partir de 1977 el Partido Socialista se divide entre renovados, a cuya cabeza estaban Carlos Altamirano y Jorge Arrate, y ortodoxos, a cuya cabeza estaba Clodomiro Almeyda.

La tendencia renovada planteaba la sustitución de la tesis del sistema socialista como dictadura del proletariado por la tesis de la democracia de trabajadores.

En esta última debía existir pluralismo político, expresado en la existencia de varios partidos.

Este enfoque también está sometido, como todos los otros, a un funcionamiento en las sombras. La diferencia consistía en que los funcionarios de FLACSO podían publicar documentos de trabajo, los cuales eran impresos a roneo, y desde 1983 libros de circulación restringida.

\section{LA IDEOLOGÍA SUSTITUTIVA}

Como se ha dicho, la dictadura plantea un doble proyecto. Este es liberal extremo en la economía y conservador en la cultura.

En los primeros días de abril de 1975 la Junta Militar decide cambiar el programa económico aplicado hasta entonces, sustituyéndolo por uno de carácter neoliberal.

Los principales propulsores de este cambio son economistas formados en la Universidad Católica, quienes habían seguido estudios de posgrado en la Universidad de Chicago. A ellos se agregan dos ingenieros civiles y un economista de la Universidad de Chile. Estos últimos habían participado del gobierno de Frei Montalva.

Los nombres de estos economistas son Sergio de Castro, Pablo Barahona, Miguel Kast, Jorge Cauas, Raúl Sáez y Álvaro Bardón.

El proyecto que imponen postula que la intervención del Estado en la economía debería dar paso a la primacía del mercado como orientación ideal.

Esta postura es paradojal, pues como se ha dicho, la dictadura militar es totalitaria, pues no solo fomenta transformaciones económicas, sino también culturales.

Justamente por ese último carácter elimina del espacio público a las ideologías socialcristianas y de izquierda.

Impone su liberalismo autoritario como modelo de largo plazo, el cual debe proyectarse aún más allá del régimen militar, creando para ello la Constitución del 80. Esta define la existencia, para después de 1988, de una democracia semirrepresentativa. 
Adquiere ese carácter porque en ella existiría el Senado mixto, con parlamentarios electos, designados y un vitalicio; un Consejo de Seguridad Nacional con mayoría de miembros militares y el sistema electoral binominal.

Ese tipo de régimen, que representaba el modelo de democracia para los militares de la dictadura, existió en Chile desde 1989 hasta el 2005, cuando a fines del gobierno de Ricardo Lagos se reforma la Constitución.

Esa era la "democracia autoritaria y tecnificada" que planteaban como ideal.

Dadas esas circunstancias, el paso de ese modelo a una democracia representativa convencional, como la existente después de 2005, constituye un avance pese a que la Constitución conserva, en muchos aspectos, el sello del régimen militar aun después de las reformas. 